\author{
E. R. Pearson - S. Pruhova $\cdot$ C. J. Tack $\cdot$ A. Johansen $\cdot$ \\ H. A. J. Castleden • P. J. Lumb - A. S. Wierzbicki • \\ P. M. Clark · J. Lebl $\cdot$ O. Pedersen $\cdot$ S. Ellard • \\ T. Hansen - A. T. Hattersley
}

\title{
Molecular genetics and phenotypic characteristics of MODY caused by hepatocyte nuclear factor $4 \alpha$ mutations in a large European collection
}

Received: 27 September 2004 / Accepted: 16 December 2004 / Published online: 14 April 2005

(C) Springer-Verlag 2005

\begin{abstract}
Aims/hypothesis: Heterozygous mutations in the gene of the transcription factor hepatocyte nuclear factor $4 \alpha(\mathrm{HNF}-4 \alpha)$ are considered a rare cause of MODY with only 14 mutations reported to date. The description of the phenotype is limited to single families. We investigated the genetics and phenotype of $H N F-4 \alpha$ mutations in a large European Caucasian collection. Methods: $H N F-4 \alpha$ was sequenced in 48 MODY probands, selected for a phenotype of $H N F-1 \alpha$ MODY but negative for $H N F-1 \alpha$
\end{abstract}

Duality of interest All authors declare that they have no duality of interest.

E. R. Pearson · H. A. J. Castleden · S. Ellard .

A. T. Hattersley $(\triangle)$

Diabetes and Vascular Medicine, Institute of Biomedical and Clinical Science, Peninsula Medical School,

Barrack Road,

Exeter, EX2 5AX, UK

e-mail: a.t.hattersley@exeter.ac.uk

Tel.: +44-139-2406807

Fax: $+44-139-2406767$

S. Pruhova $\cdot$ J. Lebl

Department of Paediatrics, 3rd Faculty of Medicine,

Charles University,

Prague, Czech Republic

C. J. Tack

Division of General Internal Medicine,

541, University Medical Centre Nijmegen,

Nijmegen, The Netherlands

A. Johansen · O. Pedersen $\cdot$ T. Hansen

Steno Diabetes Centre and Hagedorn Research Institute,

Gentofte,

Copenhagen, Denmark

P. J. Lumb · A. S. Wierzbicki

Department of Chemical Pathology, St Thomas' Hospital,

London, UK

P. M. Clark

Regional Endocrine Laboratories,

University Hospital Birmingham,

Birmingham, UK mutations. Clinical characteristics and biochemistry were compared between $54 H N F-4 \alpha$ mutation carriers and 32 familial controls from ten newly detected or previously described families. Results: Mutations in $H N F-4 \alpha$ were found in 14/48 (29\%) probands negative for $H N F-1 \alpha$ mutations. The mutations found included seven novel mutations: S34X, D206Y, E276D, L332P, I314F, L332insCTG and IVS5nt $+1 \mathrm{G}>\mathrm{A}$. I314F is the first reported de novo $H N F-4 \alpha$ mutation. The average age of diagnosis was 22.9 years with frequent clinical evidence of sensitivity to sulphonylureas. Beta cell function, but not insulin sensitivity, was reduced in diabetic mutation carriers compared to control subjects (homeostasis model assessment of beta cell function $29 \% p<0.001$ vs controls). $H N F-4 \alpha$ mutations were associated with lower apolipoprotein $\mathrm{A} 2(p=0.001)$, A1 $(p=0.04)$ and total HDL-cholesterol $(p=0.02)$ than in control subjects. However, in contrast to some previous reports, levels of triglycerides and apolipoprotein C3 were normal. Conclusions/interpretation: $H N F-4 \alpha$ mutations are common when no HNF-1 $\alpha$ mutation is found in strictly defined MODY families. The HNF- $4 \alpha$ clinical phenotype and beta cell dysfunction are similar to HNF-1 $\alpha$ MODY and are associated with reduced apolipoprotein A2 levels. We suggest that sequencing of $H N F-4 \alpha$ should be performed in patients with clinical characteristics of HNF-1 $\alpha$ MODY in whom mutations in $H N F-1 \alpha$ are not found.

Keywords Apolipoprotein A1 - Apolipoprotein A2 . Diabetes - Hepatocyte nuclear factor $4 \alpha \cdot \mathrm{HNF}-4 \alpha$. MODY $\cdot \mathrm{P} 2$ promoter $\cdot$ Transcription factors

Abbreviations Apo: Apolipoprotein $\cdot \mathrm{HNF}-4 \alpha$ : Hepatocyte nuclear factor $4 \alpha \cdot$ HOMA: Homeostasis model assessment $\cdot$ Lp: Lipoprotein

\section{Introduction}

The orphan nuclear receptor hepatocyte nuclear factor $4 \alpha$ $(\mathrm{HNF}-4 \alpha)$ plays a fundamental role in the complex tran- 
scription factor network that regulates liver and pancreatic islet development and function [1]. In mice, homozygous knockout of $H N F-4 \alpha$ (the gene encoding HNF-4 $\alpha$ ) is lethal at an early embryonic stage; however, the heterozygous knockout has no phenotype. In humans, heterozygous mutations in $H N F-4 \alpha$ cause a phenotype that is predominantly characterised by MODY [2].

Despite the description of $H N F-4 \alpha$ mutations as a cause of MODY in 1996 [2], only 11 coding region mutations and one splice site mutation (in 13 families) have been published in MODY families: F75fsdelT [3]; K99fsdelAA [4]; G115S [5]; V121I [6]; R125W [7]; R127W [8, 9]; R154X [10]; V199I [11]; R244Q [7]; Q268X [2]; E276Q [12]; IVS5-2delA [13]. More recently, a pancreatic specific P2 promoter $46 \mathrm{~kb}$ upstream of the $H N F-4 \alpha$ transcription start site has been identified [14]. Two mutations in this $\mathrm{P} 2$ promoter have been described: $-181 \mathrm{G}>\mathrm{A}[15]$ in an HNF-1 $\alpha$ binding site; and $-146 \mathrm{~T}>\mathrm{C}$ [14] in an IPF-1 (PDX-1) binding site. Additionally, a balanced translocation with a breakpoint between the $\mathrm{P} 2$ promoter and the $H N F-4 \alpha$ gene has also been shown to cause MODY [16]. The small number of mutations in $H N F-4 \alpha$ is in contrast to more than 120 in $H N F-1 \alpha$ [17] and 195 mutations (281 families) in glucokinase [18]. HNF-4 $\alpha$ mutations are reported to have a prevalence of between 2 and $5 \%$ of all MODY cases [5, 7, 19]. Diagnostic genetic services for diabetes frequently only offer $H N F-1 \alpha$ and glucokinase testing; $H N F-4 \alpha$ is rarely tested.

In the pancreas HNF- $1 \alpha$ activates transcription of HNF$4 \alpha$, via the P2 promoter, which in turn activates HNF- $1 \alpha$ transcription. It has been proposed that this feed-forward loop acts as a bistable switch [20], such that haploinsufficiency of either HNF- $1 \alpha$ or HNF- $4 \alpha$ causes the switch to turn off. This model predicts a similar pancreatic phenotype for $H N F-1 \alpha$ and $H N F-4 \alpha$ mutations. In the liver the picture is not as clear, with some studies reporting primarily P1 transcripts [15] and other studies reporting both P1- and P2derived transcripts $[1,14]$. The $\mathrm{P} 1$ promoter does not contain an HNF- $1 \alpha$ binding site so the feed-forward loop seen in the pancreas plays a lesser or no role in the liver. Thus a different 'hepatic' phenotype (e.g. lipid metabolism) might be predicted to result from $H N F-1 \alpha$ and $H N F-4 \alpha$ mutations.

To date, published phenotypic data on $H N F-4 \alpha$ mutation carriers is of single families - notably the extensively studied 'RW' family in whom $H N F-4 \alpha$ mutations were first described [2]. In the RW family, carrying the Q268X mutation, the primary defect was established as decreased beta cell insulin secretion with normal insulin sensitivity [21, 22], decreased alpha cell [23] and decreased delta cell [24] function. Similarly, a Swedish family (DS) has been well characterised with normal insulin-stimulated glucose uptake in a euglycaemic clamp, and decreased beta cell response to glucagon, intravenous glucose, oral glucose and a test meal [4]. In these two families $H N F-4 \alpha$ mutation carriers have low circulating triglycerides and apolipoprotein (Apo) concentrations $[4,25]$. Consistent with this, a liverspecific HNF- $4 \alpha$ knockout mouse has reduced fasting serum levels of total cholesterol, HDL, triglycerides and
Apos, suggesting a role of hepatic HNF- $4 \alpha$ in lipid homeostasis [26]. However, three other families with $H N F-4 \alpha$ mutation carriers had normal fasting levels of triglycerides $[3,10,11]$ and lipoproteins $[10,11]$, although these studies were smaller.

Rare mutations in $H N F-4 \alpha$ have been found in type 2 diabetes $[27,28]$, but recently a more prevalent role in the susceptibility to type 2 diabetes has been described. In two studies, a haplotype spanning the $H N F-4 \alpha$ P2 promoter was associated with type 2 diabetes with odds ratios of 1.33 [29] and 1.45 [30]. Thus, not only do HNF-4 $\alpha$ mutations cause MODY, but common variation within the regulatory region of this gene is associated with a genetic predisposition to type 2 diabetes. Therefore, understanding the monogenic phenotype may provide insight into the role of the $H N F-4 \alpha$ gene in the more complex type 2 diabetes.

The aims of our study were to define the molecular genetics of $H N F-4 \alpha$ in probands selected on the basis of clinical criteria and who did not have mutations in the $H N F-1 \alpha$ gene. We also aimed to assess pancreatic function and lipid metabolism in the largest reported collection of families with MODY caused by $H N F-4 \alpha$ mutations.

\section{Subjects and methods}

Molecular genetics Clinical referrals for MODY genetic testing to the UK Exeter laboratory between 1997 and 2004 were selected on the basis of the following clinical criteria:

1) at least one family member diagnosed with type 2 diabetes by WHO criteria before 25 years of age

2) at least a two-generation family history of diabetes

3) absence of features suggestive of young-onset type 2 diabetes, namely marked insulin resistance and obesity $\left(\mathrm{BMI}>30 \mathrm{~kg} / \mathrm{m}^{2}\right)$

4) presence of one or more of the following clinical and biochemical phenotypes suggestive of HNF- $1 \alpha$ rather than glucokinase MODY [31, 32]:

i) progressive deterioration in glucose tolerance leading to increasing hyperglycaemia and/or treatment requirements

ii) evidence of marked hyperglycaemia as shown by an $\mathrm{HbA}_{1} \mathrm{c}>4 \mathrm{SD}$ above normal

iii) fasting glucose documented below $5.5 \mathrm{mmol} / \mathrm{l}$, in a subject who subsequently developed diabetes

iv) OGTT showing an increment in glucose concentration between fasting and 120 -min values of $>4.5 \mathrm{mmol} / \mathrm{l}$

Using these criteria, 261 subjects were selected for $H N F$ $1 \alpha$ testing. Of these, 117 were found to have $H N F-1 \alpha$ mutations. $H N F-4 \alpha$ was sequenced in $48 H N F-1 \alpha$-negative probands from the remaining 144 subjects. All patients were Caucasian.

Genomic DNA was amplified using published primers for the P2 promoter [14], P1 promoter, exons 1-10 and splice sites [2]. PCR products were purified and sequenced using BigDye Terminator chemistry (Applied Biosystems, 
Warrington, UK). Reactions were analysed on an ABI Prism 377 or 3100 DNA Sequencer (Applied Biosystems) and sequences compared using Sequence Navigator software.

Subjects for clinical studies Fifty-four $H N F-4 \alpha$ mutation carriers and 32 non-mutation carriers (control subjects) were recruited from ten European Caucasian families: eight families had mutations within the coding region of $H N F$ $4 \alpha$; six British $([9,12]$, and four families from this series), one Danish [3] and one Czech [7]. Two families had mutations within the pancreatic specific $\mathrm{P} 2$ promoter: one Czech [15] and one Dutch [14]. This study was approved by the North and East Devon Local Research Ethics committee, and all participants gave written informed consent.

Methods for clinical studies Following an overnight fast, blood was collected and centrifuged within $1 \mathrm{~h}$ at $3000 \mathrm{rpm}$ for $10 \mathrm{~min}$. Serum and plasma were stored at $-70^{\circ} \mathrm{C}$. All biochemistry was performed in the same UK laboratories, samples having been transported frozen on dry ice. Patients treated with lipid-lowering agents $(n=4)$ were excluded from the analysis of biochemistry data. Children aged less than 16 years and pregnant women were excluded from all biochemical analysis. Plasma glucose and insulin levels were measured. For insulin analysis, isophane insulin was omitted for $24 \mathrm{~h}$, soluble insulin was omitted for $12 \mathrm{~h}$ and oral hypoglycaemic agents were omitted for $48 \mathrm{~h}$ prior to blood sampling. Insulin was measured by an immunoenzymometric assay (Insulin EASIA; Biosource, Nivelles, Belgium) calibrated against the International Reference Preparation 66/304 with no detectable cross-reactivity with intact proinsulin and 32-33 split proinsulin and reported as pmol/l. Serum lipids and a liver profile including transaminases were measured by standard automated methods. LDL-cholesterol was calculated by the Friedewald equation, as all triglyceride concentrations were lower than 4.5 $\mathrm{mmol} / \mathrm{l}(400 \mathrm{mg} / \mathrm{dl})$. Apolipoproteins A1, A2, B $100, \mathrm{C} 2, \mathrm{C} 3$ and lipoprotein (Lp)-a were measured by turbidimetric methods on a Cobas Fara 2 analyser (Roche, Welwyn, UK) using Dako polyclonal antisera. High-sensitivity CRP was
I

II

III

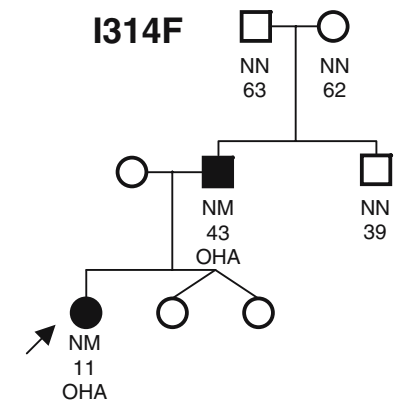

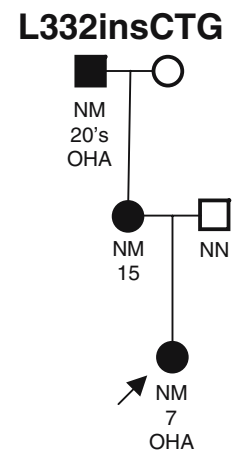

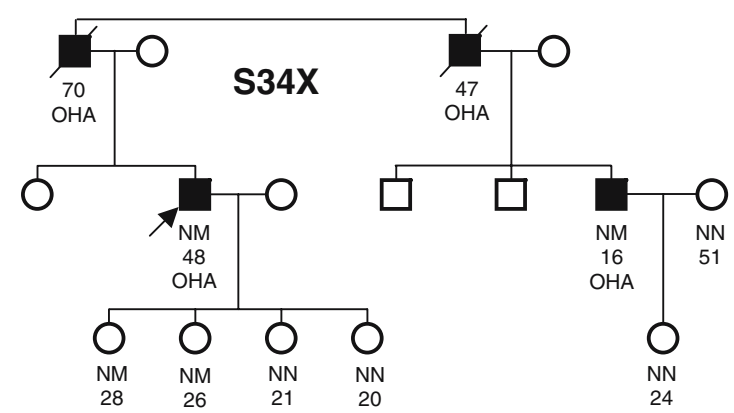

I

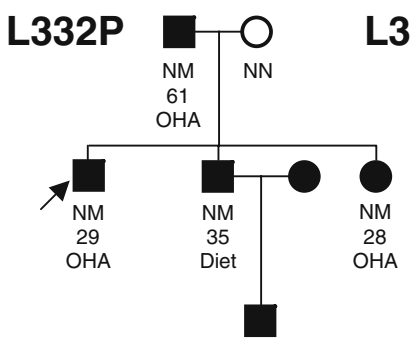

332P

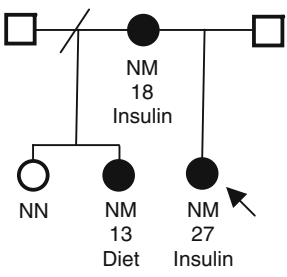

III

II
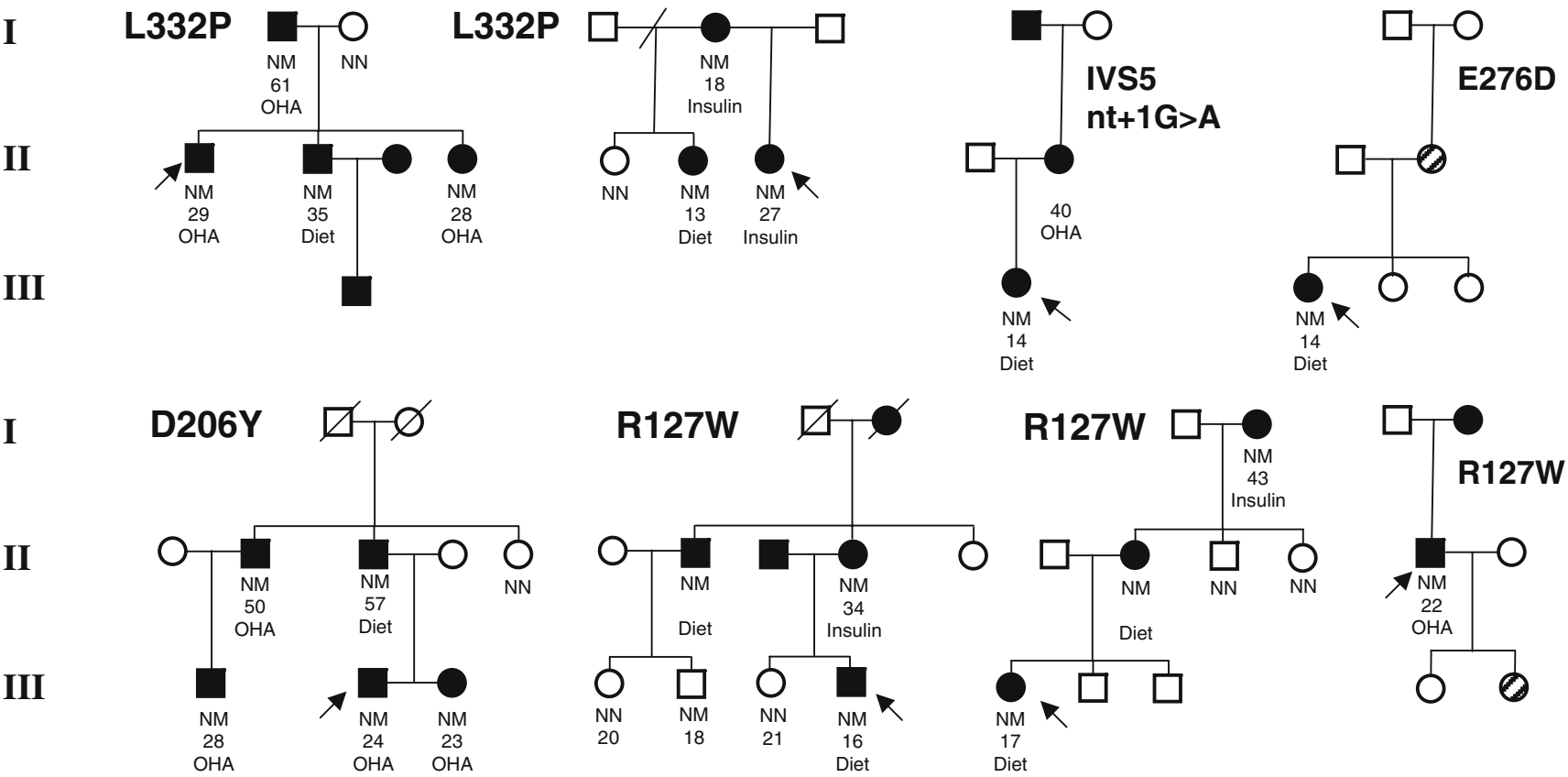

Fig. 1 Pedigrees of families with novel and unpublished $H N F-4 \alpha$ mutations. Filled symbols represent diabetes, shaded symbols represent gestational diabetes, open symbols represent no diabetes. Genotype NN, no mutation; NM, heterozygous HNF- $4 \alpha$ mutation; OHA,

oral hypoglycaemic drugs. The age is the age diagnosed with diabetes in individuals with diabetes, or current age in subjects who do not have diabetes. The treatment is diet, OHA, or insulin 
by nephelometric technique on a BN2 analyser (Dade Behring, Milton Keynes, UK).

Calculation of insulin sensitivity and beta cell function Insulin sensitivity and beta cell function were determined using the homeostasis model assessment (HOMA) computer model $[33,34]$.

Statistical analysis Where data showed a skewed distribution, they were log-transformed to normality. $H N F-4 \alpha$ coding and P2 mutation groups were analysed together and compared with familial controls. Baseline characteristics and measures of beta cell function and insulin sensitivity were compared using independent samples $t$-test and chi square test. Comparison of lipid and liver enzyme biochemistry was by univariate analysis using HNF- $4 \alpha$ genotype and family number as fixed factors. An effect of genotype on a biochemical marker was only taken to be significant if the HNF- $4 \alpha$ genotype $p$ value was less than 0.05 with no significant interaction between factors.

\section{Results}

Molecular genetics $H N F-4 \alpha$ mutations were found in 14/48 (29\%) of probands who were negative for $H N F-1 \alpha$ mutations. Of these, three pedigrees have been previously described: E276Q [12], R127W [9], P2-146T>C [14]; three further probands were found to have the R127W mutation, and eight probands had seven novel mutations: S34X, D206Y, E276D, I314F, L332P (two families), L332insCTG and IVS5nt $+1 \mathrm{G}>\mathrm{A}$. The pedigrees showing age of diagnosis and treatment for these novel mutations and unpublished R127W mutations are shown in Fig. 1. Microsatellite analysis [35] confirmed that $\mathrm{I} 314 \mathrm{~F}$ mutation is a de novo $H N F-4 \alpha$ gene mutation.

Clinical and biochemical phenotypes The clinical characteristics of the $54 H N F-4 \alpha$ mutation carriers and 32 familial control subjects for the phenotype study are shown in Table 1. Both groups were well matched for age and BMI. The HNF-4 $\alpha$ mutation carriers consisted of 42 diabetic subjects diagnosed at a mean of 22.9 years (range 548 ) and 12 subjects who did not have diabetes (no treatment and fasting glucose $<7 \mathrm{mmol} / \mathrm{l}$ ). The non-diabetic mutation carriers' mean age was 22.6 (range 9-38) and they had a similar BMI and WHR to the diabetic subjects, despite being younger. Accounting for family of origin had no effect on these results. The non-diabetic mutation carriers were from six families and age of onset had no correlation with site or type of mutation within the gene (data not shown). Twenty two patients were known to have received sulphonylureas and ten (45\%) showed clinical features suggestive of a good hypoglycaemic response to this treatment: six are being managed with low doses of sulphonylureas (requiring $12.5 \%$ or less of the maximum licensed dose); two patients are still being treated with sulphonylureas after 33 and 34 years of treatment; and two patients
Table 1 Baseline characteristics of patients with $H N F-4 \alpha$ mutations and matched familial controls

\begin{tabular}{|c|c|c|c|}
\hline & $\mathrm{HNF}-4 \alpha$ & Control & $p$ value \\
\hline Number & 54 & 32 & \\
\hline Mutations & $\begin{array}{l}\text { S34X, F75fsdelT, } \\
\text { R127W*3, D206C, } \\
\text { E276Q, I314F, } \\
-181 \mathrm{G}>\mathrm{A},-146 \mathrm{~T}>\mathrm{C}\end{array}$ & & \\
\hline Age (range) years & $38.9(9-78)$ & $35.3(11-63)$ & 0.30 \\
\hline Sex male/female & $19 / 35$ & $17 / 15$ & 0.18 \\
\hline BMI (SD) kg/m² & $25.1(3.7)$ & $25.0(3.7)$ & 0.92 \\
\hline Male/female & $25.3 / 25.0$ & $25.9 / 24.1$ & \\
\hline WHR (SD) & $0.87(0.13)$ & $0.88(0.10)$ & 0.76 \\
\hline Male/female & $0.92 / 0.85$ & $0.93 / 0.82$ & \\
\hline \multicolumn{4}{|l|}{ Diabetes } \\
\hline Number & 42 & & \\
\hline Sex male/female & $17 / 25$ & & \\
\hline Age (range) years & $43.9(14-78)$ & & \\
\hline $\begin{array}{l}\text { Age diagnosed } \\
\text { (range) }\end{array}$ & $22.8(5-48)$ & & \\
\hline BMI (SD) kg/m² & $25.7(3.5)$ & & \\
\hline WHR (SD) & $0.89(0.14)$ & & \\
\hline $\begin{array}{l}\text { Treatment none/ } \\
\text { OHA/insulin } \\
\text { (in \%) }\end{array}$ & $10 / 50 / 40$ & & \\
\hline \multicolumn{4}{|l|}{ No diabetes } \\
\hline Number & 12 & & \\
\hline Sex male/female & $2 / 10$ & & \\
\hline Age (range) years & $22.6(9-38)$ & & \\
\hline BMI (SD) kg/m² & $23.2(4.16)$ & & \\
\hline WHR (SD) & $0.81(0.07)$ & & \\
\hline
\end{tabular}

$O H A$ oral hypoglycaemic agent

were treated with sulphonylureas for 28 and 37 years before requiring insulin.

The fasting plasma insulin, glucose and HOMA B (beta cell function) and $\mathrm{S}$ (insulin sensitivity) indices are shown in Table 2. The diabetic group had decreased beta cell function but normal insulin sensitivity compared to control subjects. The non-diabetic group of $H N F-4 \alpha$ mutation carriers had similar beta cell function and insulin sensitivity compared with control subjects. The levels of fasting serum lipids in the $H N F-4 \alpha$ mutation carriers and control subjects are shown in Table 3. HDL-cholesterol $(p=0.023)$, ApoA1 $(p=0.042)$ and ApoA2 ( $p=0.001)$ were reduced in the mutation carriers (HNF- $4 \alpha$ genotype) independently of variation between the families. This suggests that a specific reduction in the Lp A1-A2 sub-fraction of HDL occurs in patients with $H N F-4 \alpha$ mutations. Interestingly, there was no significant effect of genotype on fasting serum levels of triglycerides although there was a highly significant interaction $(p<0.001)$ between the genotype and family factors, meaning that the effect of the HNF- $4 \alpha$ genotype on triglycerides varies between families. LDL-cholesterol $(p=0.01)$ and $\mathrm{ApoB}_{100}(p=0.02)$ were increased in mutation carriers 
Table 2 Fasting serum insulin levels and HOMA-B and -S indices of patients with $H N F-4 \alpha$ mutations divided by presence or absence of diabetes and familial controls

\begin{tabular}{lccccc}
\hline & \multicolumn{2}{l}{ HNF-4 $\alpha$} & Control & & $p$ value \\
\cline { 2 - 3 } & Diabetes & Non-diabetes & & Diabetes vs control & Non-diabetes vs control \\
\hline Number & 29 & 5 & 29 & & 0.65 \\
Glucose mmol/1 & $10.0(4.4)$ & $4.8(0.6)$ & $5.0(0.7)$ & $<0.001$ & 0.885 \\
Insulin pmol/1 & $74(49-111)$ & $79(47-132)$ & $93(56-154)$ & 0.06 & 0.49 \\
HOMA B \% of control & $29(15-56)$ & $97(68-139)$ & $100(67-160)$ & $<0.001$ & 0.52 \\
HOMA S \% of control & $100(60-168)$ & $118(71-196)$ & $100(62-162)$ & 0.975 & \\
\hline
\end{tabular}

Data presented as mean (SD) or geometric mean (SD range)

Table 3 Biochemical profiles of patients with $H N F-4 \alpha$ mutations and matched familial controls
Data are presented as mean (SD) or geometric mean (SD range) ${ }^{a}$ Results where the HNF- $4 \alpha$ genotype is significant at $p<0.05$ with no significant interaction family*genotype. $A L P$ alkaline phosphatase, $A L T$ alanine aminotransferase

\begin{tabular}{|c|c|c|c|c|}
\hline & \multirow[t]{2}{*}{$\mathrm{HNF}-4 \alpha$} & \multirow[t]{2}{*}{ Control } & \multicolumn{2}{|c|}{ ANOVA $p$ value } \\
\hline & & & Family & HNF- $4 \alpha$ genotype \\
\hline Number & 42 & 29 & & \\
\hline Age years & $40.6(15.1)$ & $37.5(12.6)$ & 0.89 & 0.31 \\
\hline Sex male/female & $28 / 16$ & $14 / 15$ & & \\
\hline BMI kg/m² & $25.3(3.6)$ & $25.4(3.5)$ & 0.018 & 0.79 \\
\hline Glucose, $\mathrm{mmol} / \mathrm{l}^{\mathrm{a}}$ & $9.1(4.3)$ & $5.0(0.61)$ & 0.13 & $<0.001$ \\
\hline Total cholesterol, mmol/1 & $5.5(1.0)$ & $5.4(1.1)$ & 0.07 & 0.23 \\
\hline HDL-cholesterol, mmol/ $1^{\mathrm{a}}$ & $1.5(0.46)$ & $1.8(0.42)$ & 0.024 & 0.023 \\
\hline LDL-cholesterol, mmol/1 & $3.4(2.5-4.5)$ & $2.9(2.1-3.9)$ & 0.006 & 0.011 \\
\hline Triglycerides, mmol/1 & $1.13(0.66-1.94)$ & $1.12(0.72-1.72)$ & 0.001 & 0.09 \\
\hline ApoA1, g/1 ${ }^{\mathrm{a}}$ & $1.48(0.29)$ & $1.65(0.28)$ & 0.016 & 0.042 \\
\hline ApoA2, g/1 ${ }^{\mathrm{a}}$ & $0.33(0.07)$ & $0.40(0.08)$ & 0.006 & 0.001 \\
\hline $\mathrm{ApoB}, \mathrm{g} / \mathrm{l}^{\mathrm{a}}$ & $0.95(0.21)$ & $0.86(0.27)$ & 0.012 & 0.019 \\
\hline ApoC2, mg/dl & $2.93(1.82-4.72)$ & $1.61(1.07-2.4)$ & 0.162 & 0.55 \\
\hline ApoC3, mg/dl & $13.3(4.36)$ & $14.7(3.3)$ & 0.001 & 0.85 \\
\hline $\mathrm{Lp}(\mathrm{a}), \mathrm{g} / \mathrm{l}$ & $0.095(0.03-0.28)$ & $0.095(0.04-0.25)$ & 0.032 & 0.85 \\
\hline hsCRP, mg/l & $1.24(0.44-3.46)$ & $0.93(0.42-2.08)$ & 0.026 & 0.245 \\
\hline ALT, IU/1 & $16(9-27)$ & $21(13-34)$ & $<0.001$ & 0.53 \\
\hline ALP, IU/1 & $63(40-98)$ & $67(43-103)$ & 0.13 & 0.38 \\
\hline Bilirubin, $\mu \mathrm{mol} / 1$ & $12(7-21)$ & $12(8-17)$ & 0.09 & 0.89 \\
\hline Albumin, g/l & $45(3)$ & $47(3)$ & 0.16 & 0.25 \\
\hline
\end{tabular}

consistent with the observed decrease in reverse cholesterol transport associated Lps, although again there was a significant interaction between the genotype and family factors making interpretation of these results difficult. No differences were found in fasting serum concentrations of triglycerides, ApoC2, ApoC3 or lipoprotein(a).

\section{Discussion}

We have described 11 previously unreported families with mutations in $H N F-4 \alpha$, including seven novel mutations and the first description of a spontaneous mutation in this gene. We highlight that sequencing $H N F-4 \alpha$ is important in families with clinical characteristics suggestive of HNF-1 $\alpha$ MODY who do not have an $H N F-1 \alpha$ mutation. We have also characterised the diabetes phenotype and lipid phenotype in a large European collection of patients, and confirm reports from individual families of decreased beta cell function, normal insulin sensitivity and reduced ApoA2 (HDL LpA1-A2) in $H N F-4 \alpha$ mutation carriers.
The $H N F-4 \alpha$ mutations occurring in previously unreported families are S34X, R127W (three families), D206Y, E276D, L332P (two families), I314F, L332insCTG, and IVS5nt $+1 \mathrm{G}>\mathrm{A}$. Only R127W has been reported before; this was seen in one UK and one Japanese family and is now the most common mutation described in $H N F 4-\alpha$. The position of these mutations and previously published mutations are shown in Fig. 2. The nonsense mutation S34X will result in a truncated protein with marked loss of HNF- $4 \alpha$ function, as it lacks a transactivating domain. The intronic mutation IVS5nt $+1 \mathrm{G}>\mathrm{A}$ is at a splice donor site and likely to be pathogenic. The E276D missense mutation occurs at the same amino acid as the previously reported E276Q. The other missense mutations (D206Y, L332P and I314F) and the in-frame insertion (L332insCTG) are also likely to be pathogenic as there is conservation of the amino acid residues involved between human, rat, mouse and xenopus; and they co-segregate with diabetes in families. It is impossible to completely rule out that these are rare polymorphisms without performing functional studies, especially as some families are small and so co-segregation could occur 


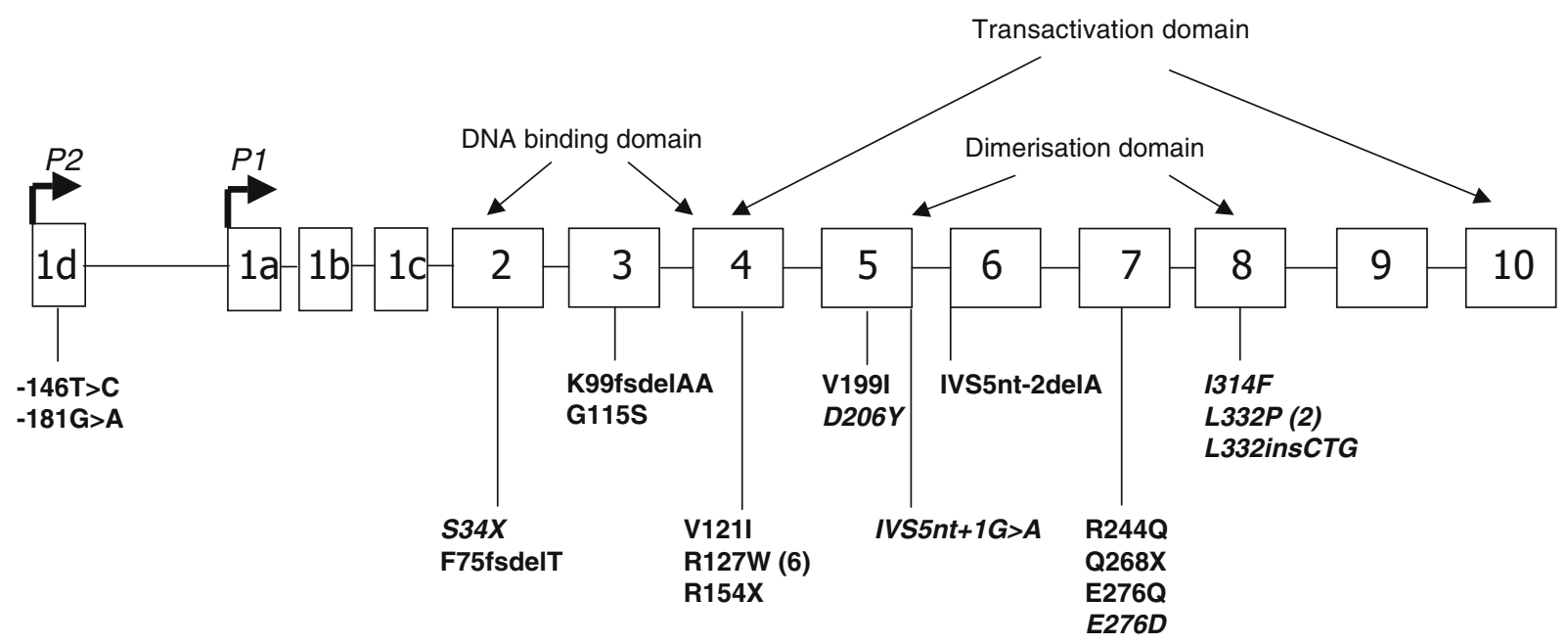

Fig. 2 Diagram to show the location of the 20 reported $H N F-4 \alpha$ gene mutations in 26 MODY families (recurrent mutations with number of families in brackets). The 13 exons of the $H N F-4 \alpha$ gene (including the alternatively spliced exons $1 \mathrm{a}, 1 \mathrm{~b}, 1 \mathrm{c}$ and $1 \mathrm{~d}$ ) and two promoters ( $\mathrm{P} 2$ and $\mathrm{P} 1)$ are shown. The $\mathrm{P} 2$ promoter is located $46 \mathrm{~kb}$

by chance. Microsatellite analysis confirmed a de novo mutation $\mathrm{I} 314 \mathrm{~F}$, and this is the first report of a spontaneous mutation in $H N F-4 \alpha$. Interestingly, two mutations in three families occurred within a polyCTG tract encoding five leucine residues (codons 328-332) and which is a likely binding site for co-regulators, including SHP which inhibits transcriptional activity of HNF- $4 \alpha[36,37]$.

We found $H N F-4 \alpha$ mutations in $29 \%$ of our MODY patients selected on the basis of clinical characteristics and not having an $H N F-1 \alpha$ mutation. This report increases the number of MODY families with $H N F-4 \alpha$ mutations from 16 to 27 . The low number of $H N F-4 \alpha$ mutations reported to date may reflect the fact that the gene is often not sequenced or that subjects with an inappropriate phenotype are tested. As our data are based on a selected group of patients, it does not represent a prevalence figure but can be used to guide protocols for clinical testing. Clinical selection can considerably reduce the amount of genotyping, especially as the two most common types of MODY, i.e. those due to $H N F-1 \alpha$ and glucokinase mutations, have markedly different phenotypes [32, 38]. We found $116(44 \%) H N F-1 \alpha$ mutations in 261 subjects referred to the UK Exeter laboratory with clinical characteristics supportive of non-glucokinase or HNF-1a MODY. Of those without an $H N F-1 \alpha$ mutation, 14 of $48(29 \%)$ tested were found to have $H N F$ $4 \alpha$ mutations. This supports a three-step approach: selection on clinical criteria; sequencing for $H N F-1 \alpha$ mutations; then, if this is negative, sequencing for $H N F-4 \alpha$ mutations.

The mean age of onset of diabetes ( $23 \mathrm{vs} 20$ years), the percentage requiring oral agents (50 vs $43 \%)$ and percentage requiring insulin ( 40 vs $31 \%$ ) were similar in this HNF$4 \alpha$ series and in a series of $H N F-1 \alpha$ mutation carriers from 59 MODY families [19]. $H N F-1 \alpha$ mutation carriers are sensitive to the hypoglycaemic effects of sulphonylurea drugs $[39,40]$. This study was not a formal study of sulphonylurea sensitivity, but the low doses used, and long upstream from the $\mathrm{P} 1$ promoter and is the predominant isoform in the pancreas. A balanced translocation with a breakpoint between the P2 promoter and exon 2 has also been reported to cause MODY [16]. P1 is the predominant promoter in the liver. Novel mutations reported in this study are shown in italics

duration of treatment would be consistent with sulphonylurea sensitivity in MODY due to $H N F-4 \alpha$ mutations. This finding of sensitivity to sulphonylureas was also apparent in a prospective study of $12 H N F-4 \alpha$ patients from the 'RW family', where insulin secretion in response to oral glucose has been markedly augmented by sulphonylureas for up to 33 years [41]. HOMA analysis suggested a marked beta cell defect in the diabetic subjects, but no reduction in insulin sensitivity. Thus, the diabetes phenotypes due to $H N F-1 \alpha$ mutations and $H N F-4 \alpha$ mutations are clinically similar. This is consistent with the prediction of Ferrer's bistable switch hypothesis [20] and supports the proposed sequential approach of sequencing $H N F-4 \alpha$ after $H N F-1 \alpha$.

The clinical and biochemical study is on the largest collection of HNF- $4 \alpha$ families collected to date. Previous studies have been on individual families and it is therefore not possible to say what is a general feature of $H N F-4 \alpha$ mutations and what is a mutation-specific effect. The strength of this study is that a large sample size, with numerous mutations, allows for applicability of results to the whole HNF- $4 \alpha$ population. However, this study is limited in that when collecting numerous families, there is large interfamilial variation in a number of the biochemistry results, despite their being analysed in a single laboratory as a single batch, which means that small genotype-specific effects could not be detected reliably.

In the pancreas, most studies report that the HNF- $4 \alpha$ transcripts present are derived exclusively from the P2 promoter $[1,14,15]$. In the liver the picture is not as clear, with some studies reporting primarily P1 transcripts [15]; or transcripts from both the $\mathrm{P} 1$ and $\mathrm{P} 2$ promoter $[1,14]$. In the former case, the MODY patients with a P2 promoter mutation would be predicted to have a normal hepatic phenotype, i.e. normal circulating levels of Apos and triglycerides; in the latter case, an intermediate phenotype might be predicted. The large variation between families 
meant that we were unable to compare the two families with $H N F-4 \alpha$ P2 promoter mutations with those families with coding mutations. However, if the mutation carriers $(n=7)$ are compared with their familial controls $(n=4)$ in the largest P2 family $(-146 \mathrm{~T}>\mathrm{C}[14])$, then serum ApoA2 levels were similar ( 0.41 vs $0.38 \mathrm{~g} / 1, p=0.54)$, as were all the other lipid variables. It is not possible to say if this reflects the small sample size or a true lack of P2 mutations to affect Apo synthesis.

HNF- $4 \alpha$ regulates Apo transcription by the liver. In an elegant study, Shih et al. [25] show firstly that loss of HNF$4 \alpha$ function in embryoid body cells results in decreased expression of ApoA1, ApoA2, ApoB and ApoC3. Secondly they report that diabetic and non-diabetic subjects from the RW family with $H N F-4 \alpha$ mutations have low serum levels of triglycerides, ApoC3, ApoA2 and lipoprotein(a). The 18 subjects with the Q268X mutation are highly homogeneous, with a mean age of onset (+SD) of diabetes of $14 \pm 1$ years while the $\mathrm{HbA}_{1} \mathrm{c}$ of the diabetic group was only $6.4 \pm 0.5 \%$. In a separate study six carriers of the K99fsdelAA mutation [4] also had low serum levels of ApoC3 and triglycerides, but ApoA2 levels were normal. In the mouse, a liver-specific knockout had low serum HDL-C, LDL-C and triglycerides; and reduced expression of ApoA2, ApoA4, ApoC2 and ApoC3 in the liver [26]. By contrast, six subjects with the R154X mutation [10] and three subjects with a R127W mutation in $H N F-4 \alpha$ had normal serum triglycerides and Apos and elevated Lp(a); and three subjects with the V199I [11] mutation had normal serum triglycerides and Apos. The findings in the human studies are conflicting, but the most consistent finding from these studies and the mouse and cell models is that loss of function of $\mathrm{HNF}-4 \alpha$ is associated, at least in some families, with reduced circulating concentrations of ApoA2, ApoC3 and triglycerides.

In this study we show a highly significant reduction in serum ApoA2 in $H N F-4 \alpha$ mutation carriers. This is in keeping with the literature and suggests that this is a consistent finding across different mutations. Ours is the only study on human subjects to show a lower serum HDL-cholesterol in $H N F-4 \alpha$ mutation carriers than in control subjects. This may reflect the unusually high serum HDL-cholesterol (1.8 $\mathrm{mmol} / \mathrm{l}$ ) in the control group, although low serum HDLcholesterol has been described in the knockout mouse [26]. Serum ApoA2 is a major component of HDL and these are correlated in our data $(r=0.48, p<0.001)$; it is likely that the low total serum HDL-cholesterol is secondary to a low transcription of ApoA2 and a specific deficiency in the serum LpA1-A2 subfraction of HDL. It is interesting that two published $H N F-4 \alpha$ mutations are associated with low levels of serum triglycerides and $\mathrm{ApoC} 3$, and three are not, indicating variable effects of HNF- $4 \alpha$ on triglyceride-rich remnant lipoprotein metabolism. No significant correlation of genotype with serum triglyceride levels was seen in this study. This may reflect the heterogeneity in our group, and the fact that the diabetes control was not as tight as in the study by Shih et al. [25]. However, the highly significant interaction between the family (hence mutation) factor and the genotype might suggest a genotype/phenotype corre- lation between type or site of mutation and serum triglyceride and ApoC3 levels. The normal serum triglyceride levels in the $H N F-4 \alpha$ mutation carriers in this study mean that, clinically, serum triglyceride levels are not a useful phenotypic marker for $H N F-4 \alpha$ mutations.

Two studies in a Finnish [29] and Ashkenazi-Jewish [30] population show an association between a haplotype spanning the $H N F-4 \alpha$ P2 promoter and type 2 diabetes. The Finnish study looked at quantitative traits in unaffected offspring, and showed that the risk allele at SNP rs2144908 was associated with decreased beta cell function, normal insulin sensitivity and normal serum lipid concentrations. Serum HDL-cholesterol was also normal in this group, although it was lower in the spouse controls who were homozygous for the risk allele. These results are similar to those seen in our study of monogenic $H N F-4 \alpha$ mutations. Thus studying a monogenic phenotype may provide insight into a polygenic disease. It would be interesting to study circulating ApoA2 levels and HDL-lipoprotein subfraction profiles according to SNP rs2144908 genotype, as studies in monogenic disease would predict reduced levels in those carrying the risk allele.

In conclusion, we have shown that $H N F-4 \alpha$ mutations are common when $H N F-1 \alpha$ sequencing is negative in strictly defined MODY families and report eleven unpublished (including seven novel) mutations. The HNF- $4 \alpha$ MODY clinical phenotype and beta cell dysfunction are similar to HNF-1 $\alpha$ MODY. A consistent deficiency in the fasting serum ApoA2 level and consequently HDL LpA1A2 level was seen in our large collection of HNF- $4 \alpha$ families and probably reflects a direct effect of reduced HNF- $4 \alpha$ on ApoA2 synthesis in the liver. We suggest that in patients with clinical characteristics of HNF-1 $\alpha$ MODY, $H N F-4 \alpha$ should be sequenced, if a mutation is not found in the $H N F$ $1 \alpha$ gene.

Acknowledgements This study was funded by the Wellcome Trust. E. R. Pearson holds a Wellcome Trust clinical training fellowship, and A. T. Hattersley a Wellcome Trust career leave fellowship. C. J. Tack is a recipient of a clinical research fellowship of the Dutch Diabetes Foundation. The collection of Danish samples was supported by grants from the Danish Diabetes Association and The Danish Medical Research Council and the collection of Czech samples was funded by grant IGA Mzd CR NB 7420-3. The molecular genetic analysis was performed by Julie Evans, Kate Thomson, Kevin Colclough and Simon Mitchell. We would like to acknowledge all the patients and their referring clinicians.

\section{References}

1. Odom DT, Zizlsperger N, Gordon DB et al (2004) Control of pancreas and liver gene expression by HNF transcription factors. Science 303:1378-1381

2. Yamagata K, Furuta H, Oda N et al (1996) Mutations in the hepatocyte nuclear factor 4 alpha gene in maturity-onset diabetes of the young (MODY1). Nature 384:458-460

3. Moller AM, Dalgaard LT, Ambye L et al (1999) A novel Phe 75 fsdelT mutation in the hepatocyte nuclear factor-4alpha gene in a Danish pedigree with maturity-onset diabetes of the young. J Clin Endocrinol Metab 84:367-369 
4. Lehto M, Bitzen PO, Isomaa B et al (1999) Mutation in the HNF-4 alpha gene affects insulin secretion and triglyceride metabolism. Diabetes 48:423-425

5. Malecki MT, Yang Y, Antonellis A et al (1999) Identification of new mutations in the hepatocyte nuclear factor 4alpha gene among families with early onset type 2 diabetes mellitus. Diabet Med 16:193-200

6. Monney CT, Kaltenrieder V, Cousin P, Bonny C, Schorderet DF (2002) Large family with maturity-onset diabetes of the young and a novel V121I mutation in HNF4A. Human Mutat 20:230231

7. Pruhova S, Ek J, Lebl J et al (2003) Genetic epidemiology of MODY in the Czech republic: new mutations in the MODY genes HNF-4alpha, GCK and HNF-1alpha. Diabetologia 46: 291-295

8. Furuta H, Iwasaki N, Oda N et al (1997) Organization and partial sequence of the hepatocyte nuclear factor-4 $\alpha /$ MODY 1 gene and identification of a missense mutation R127W, in a Japanese family with MODY. Diabetes 46:1652-1657

9. Bulman MP, Ellard S, Hattersley AT (2000) R127W in HNF4alpha is a loss-of-function mutation causing maturityonset diabetes of the young (MODY) in a UK Caucasian family. Diabetologia 43:1203

10. Lindner T, Gragnoli C, Furuta H et al (1997) Hepatic function in a family with a nonsense mutation (R154X) in the hepatocyte nuclear factor-4 $\alpha$ /MODY1 gene. J Clin Invest 100:1400-1405

11. Gragnoli C, von Preussenthal GM, Habener JF (2004) Triple genetic variation in the HNF-4alpha gene is associated with early-onset type 2 diabetes mellitus in a Philippino family. Metabolism 53:959-963

12. Bulman M, Dronsfield MJ, Frayling T et al (1997) A missense mutation in the hepatocyte nuclear factor 4 alpha gene in a UK pedigree with maturity-onset diabetes of the young. Diabetologia 40:859-863

13. Barrio R, Bellanne-Chantelot C, Moreno JC et al (2002) Nine novel mutations in maturity-onset diabetes of the young (MODY) candidate genes in 22 Spanish families. J Clin Endocrinol Metab $87: 2532-2539$

14. Thomas H, Jaschkowitz K, Bulman M et al (2001) A distant upstream promoter of the HNF-4alpha gene connects the transcription factors involved in maturity-onset diabetes of the young. Hum Mol Genet 10:2089-2097

15. Hansen SK, Parrizas M, Jensen ML et al (2002) Genetic evidence that HNF-1alpha-dependent transcriptional control of HNF-4alpha is essential for human pancreatic beta cell function. J Clin Invest 110:827-833

16. Gloyn AL, Ellard S, Shepherd M et al (2002) Maturity-onset diabetes of the young caused by a balanced translocation where the $20 \mathrm{q} 12$ break point results in disruption upstream of the coding region of hepatocyte nuclear factor-4alpha (HNF4A) gene. Diabetes 51:2329-2333

17. Fajans SS, Bell GI, Polonsky KS (2001) Molecular mechanisms and clinical pathophysiology of maturity-onset diabetes of the young. N Engl J Med 345:971-980

18. Gloyn AL (2003) Glucokinase (GCK) mutations in hyper- and hypoglycemia: maturity-onset diabetes of the young, permanent neonatal diabetes, and hyperinsulinemia of infancy. Human Mutat 22:353-362

19. Frayling TM, Evans JC, Bulman MP et al (2001) Beta-cell genes and diabetes: molecular and clinical characterization of mutations in transcription factors. Diabetes 50:S94-S100

20. Ferrer J (2002) A genetic switch in pancreatic beta-cells: implications for differentiation and haploinsufficiency. Diabetes 51:2355-2362

21. Byrne MM, Sturis J, Fajans SS et al (1995) Altered insulin secretory responses to glucose in subjects with a mutation in the MODY1 gene on chromosome 20. Diabetes 44:699-704

22. Herman WH, Fajans SS, Ortiz FJ et al (1994) Abnormal insulin secretion, not insulin resistance, is the genetic or primary defect of MODY in the RW pedigree. Diabetes 43:40-46
23. Herman WH, Fajans SS, Smith MJ et al (1997) Diminished insulin and glucagon secretory responses to arginine in nondiabetic subjects with a mutation in the hepatocyte nuclear factor-4alpha/MODY1 gene. Diabetes 46:1749-1754

24. Ilag LL, Tabaei BP, Herman WH et al (2000) Reduced pancreatic polypeptide response to hypoglycemia and amylin response to arginine in subjects with a mutation in the HNF-4alpha/MODY1 gene. Diabetes 49:961-968

25. Shih DQ, Dansky HM, Fleisher M et al (2000) Genotype/ phenotype relationships in HNF-4alpha/MODY1: haploinsufficiency is associated with reduced apolipoprotein (AII), apolipoprotein (CIII), lipoprotein(a), and triglyceride levels. Diabetes 49:832-837

26. Hayhurst GP, Lee YH, Lambert G, Ward JM, Gonzalez FJ (2001) Hepatocyte nuclear factor 4alpha (nuclear receptor 2A1) is essential for maintenance of hepatic gene expression and lipid homeostasis. Mol Cell Biol 21:1393-1403

27. Hani EH, Suaud L, Boutin P et al (1998) A missense mutation in hepatocyte nuclear factor-4 alpha, resulting in a reduced transactivation activity, in human late-onset non-insulin-dependent diabetes mellitus. J Clin Invest 101:521-526

28. Price JA, Fossey SC, Sale MM et al (2000) Analysis of the HNF4 alpha gene in Caucasian type II diabetic nephropathic patients. Diabetologia 43:364-372

29. Silander K, Mohlke KL, Scott LJ et al (2004) Genetic variation near the hepatocyte nuclear factor-4 alpha gene predicts susceptibility to type 2 diabetes. Diabetes 53:1141-1149

30. Love-Gregory LD, Wasson J, Ma J et al (2004) A common polymorphism in the upstream promoter region of the hepatocyte nuclear factor- 4 alpha gene on chromosome $20 \mathrm{q}$ is associated with type 2 diabetes and appears to contribute to the evidence for linkage in an Ashkenazi Jewish population. Diabetes 53:1134-1140

31. Stride A, Vaxillaire M, Tuomi T et al (2002) The genetic abnormality in the beta cell determines the response to an oral glucose load. Diabetologia 45:427-435

32. Pearson ER, Velho G, Clark P et al (2001) Beta-cell genes and diabetes: quantitative and qualitative differences in the pathophysiology of hepatic nuclear factor-1alpha and glucokinase mutations. Diabetes 50:S101-S107

33. Matthews DR, Hosker JP, Rudenski AS et al (1985) Homeostasis model assessment (HOMA): insulin resistance and b-cell function from fasting plasma glucose and insulin concentrations in man. Diabetologia 28:412-419

34. Levy JC, Matthews DR, Hermans MP (1998) Correct homeostasis model assessment (HOMA) evaluation uses the computer program. Diabetes Care 21:2191-2192

35. Frayling T, Walker M, McCarthy M et al (1999) Parent-offspring trios: a resource to facilitate the identification of Type 2 diabetes genes. Diabetes 48:2475-2479

36. Chang C, Norris JD, Gron H et al (1999) Dissection of the LXXLL nuclear receptor-coactivator interaction motif using combinatorial peptide libraries: discovery of peptide antagonists of estrogen receptors alpha and beta. Mol Cell Biol 19:82268239

37. Borgius LJ, Steffensen KR, Gustafsson JA, Treuter E (2002) Glucocorticoid signaling is perturbed by the atypical orphan receptor and corepressor SHP. J Biol Chem 277:49761-49766

38. Stride A, Hattersley AT (2002) Different genes, different diabetes: lessons from maturity-onset diabetes of the young. Ann Med 34:207-216

39. Pearson ER, Starkey BJ, Powell RJ et al (2003) Genetic cause of hyperglycaemia and response to treatment in diabetes. Lancet 362:1275-1281

40. Pearson ER, Liddell WG, Shepherd M, Corrall RJ, Hattersley AT (2000) Sensitivity to sulphonylureas in patients with hepatocyte nuclear factor 1 alpha gene mutations: evidence for pharmacogenetics in diabetes. Diabet Med 17:543-545

41. Fajans SS, Brown MB (1993) Administration of sulfonylureas can increase glucose-induced insulin secretion for decades in patients with maturity-onset diabetes of the young. Diabetes Care 16:1254-1261 